\title{
Reformas da educação e trabalho no Brasil: um breve histórico do ensino em migalhas
}

Reforms of education and work in Brazil: a brief history of a crumbling education

Reformas de educación y trabajo en Brasil: un breve histórico de la enseñanza en pedazos

Lilian Fávaro Alegrâncio Iwasse

Universidade Estadual do Paraná (Brasil)

https://orcid.org/0000-0002-3638-4718

http://lattes.cnpq.br/7432731201234850

coordlilianfavaro@gmail.com

Renan Bandeirante Araujo

Universidade Estadual do Paraná (Brasil)

https://orcid.org/0000-0001-6199-1061

http://lattes.cnpq.br/9293271922485263

renanbandeirante@gmail.com

Amanda Cristina Ribeiro

Universidade Estadual de Maringá (Brasil)

https://orcid.org/0000-0002-1625-2953

http://lattes.cnpq.br/6469646290776952

amribeiro.historia@gmail.com

\section{Resumo}

Neste artigo, analisam-se as reformas da educação pública no Brasil e sua relação com as transformações do mundo do trabalho. Discorre-se sobre a tese que alinhou a educação ao processo civilizatório, discussão suscitada pelo Manifesto dos Pioneiros de 1932 e logo interrompida pela adoção do pragmatismo tecnicista que, incipiente, orientou as reformas promovidas por Gustavo Capanema. A considerar os constrangimentos típicos das nações de desenvolvimento capitalista tardio, tem-se que as reformas da educação atendem aos imperativos dos processos produtivos e das novas técnicas de gestão de pessoas. Dessa forma, ao oferecer um ensino profissionalizante ou regular, aligeirados, este deve adequar-se à criação de uma força de trabalho necessária, daí a razão pela qual os conceitos como habilidades e competências estão a matizar a atual Base Nacional Comum Curricular do Ensino Médio. Para fundamentar o artigo, apoiou-se no referencial bibliográfico, fontes documentais e legislação sobre o tema.

Palavras-chave: Educação pública brasileira. Desenvolvimento e reformas educacionais. Educação e trabalho. 


\begin{abstract}
In this paper, the reforms of public education in Brazil and their relationship with the transformations of the working world are analyzed. The thesis that aligned education with the civilizing process is discussed, an issue raised by the 1932 Pioneers Manifesto and soon interrupted by the adoption of the incipient technical pragmatism, which guided the reforms promoted by Gustavo Capanema. When considering the typical constraints of nations of late capitalist development, education reforms that have to meet the imperatives of productive processes and new people management techniques arises. Thus, when offering vocational or regular education in a shorter time, this should fit the creation of a necessary workforce, which is why concepts such as skills and competencies are shaping the current High School National Common Curricular Base. To support this paper, we relied on the bibliographic reference, documentary sources and legislation on the subject.
\end{abstract}

Keywords: Brazilian public education. Development and educational reforms. Education and work.

\title{
Resumen
}

En este artículo se analizan las reformas de la educación pública en Brasil y su relación con las transformaciones del mundo laboral. Se discute sobre la tesis que alineó la educación con el proceso civilizador, discusión planteada por el Manifiesto de los Pioneros (1932) y luego interrumpida por la adopción del pragmatismo tecnicista que, incipiente, orientó las reformas promovidas por Gustavo Capanema. Considerando las limitaciones típicas de las naciones de desarrollo capitalista tardío, ocurre que las reformas de la educación cumplen con los imperativos de los procesos productivos y de las nuevas técnicas de gestión de personas. De esa forma, al ofrecer una enseñanza profesionalizante o regular, aligerados, ésta debe adecuarse a la creación de una fuerza laboral necesaria, razón por la cual los conceptos como habilidades y competencias están matizando la actual Base Nacional Común Curricular de la Educación Secundaria. Para fundamentar el artículo, se recurrió al referencial bibliográfico, fuentes documentales y legislación sobre el tema.

Palabras clave: Educación pública brasileña. Desarrollo y reformas educativas. Educación y trabajo. 


\section{Introdução}

De modo geral, no início do século XX, a oferta do ensino público restringia-se à parcela elitizada da população. A partir da década de 1930, como parte do redirecionamento das ações estatais com vistas à superação de uma economia baseada no café, da retomada do desenvolvimento que implicava na superação de negativos indicadores sociais como o analfabetismo, ganhou azo o debate sobre a necessidade de ampliar o acesso ao ensino público, daí a formulação de políticas educacionais associando o ensino à aprendizagem de um ofício/profissão.

No bojo dessas discussões sobre a necessidade de superação de uma economia nacional predominantemente agrícola, é que devemos apreender os múltiplos significados sociais relacionados à publicação do Manifesto dos Pioneiros de 1932 e dos princípios que fundaram a Escola Nova no Brasil. A relevância histórica do Manifesto de 1932 pode ser conferida em duas premissas fundamentais que norteou o documento: a) o direito inalienável de acesso dos indivíduos à educação pública; b) a educação como pressuposto indelével do processo civilizatório, ingrediente indispensável para o desenvolvimento da nação.

A considerarem as contradições de desenvolvimento tardio do capitalismo brasileiro (ARAÚJO, 2018), menos de uma década após a publicação do Manifesto, as reformas educacionais empreendidas na década de 1940 por Gustavo Capanema implicaram a reformulação curricular e a reorganização da educação. A prioridade conferida ao ensino profissional, em conformidade aos princípios da formação tecnicista do período, negou que amplos segmentos de trabalhadores obtivesse o acesso a uma educação focada no ensino humanista e científico, conformando a outra faceta do ensino dual tal qual asseverou Saviani (2009). Desse modo, embasada por uma perspectiva tecnicista, a reforma implicou o fortalecimento da educação pública na sua forma útil instrumental.

Seguindo as trilhas do desenvolvimento tardio, a consolidação do sistema produtivo taylorista/fordista relacionado ao perfil da indústria instalada no período do Governo de Juscelino Kubitscheck (1956-1961) contribuiu para um industrialismo subordinado ao capital internacional monopolista ligado aos setores de bens de consumo duráveis e bens de produção. Em acordo com essa lógica produtiva, disseminou-se uma educação de base tecnicista que, posteriormente, ancorada nos pressupostos da teoria do capital humano, foi exaustivamente difundida ao longo dos governos militares (1964-1985). Resguardadas as suas especificidades históricas, em comum, essas reformas afirmaram o processo de negação da formação omnilateral do indivíduo humano genérico.

Este artigo, a considerar a particularidade de cada momento histórico que acompanhou a discussão sobre a educação pública no Brasil, discorre sobre a relação entre as reformas educacionais e os processos sociais, políticos e econômicos, de modo a destacar sua permanente subordinação aos imperativos do mundo do trabalho. Vista em sua processualidade dialética, seja a reforma Capanema ou o tecnicismo que marcou a educação nas décadas posteriores, até as reformas preconizadas pela Lei $\mathrm{N}^{\circ} 13.415$, de 13 de fevereiro de 2017, que conferiu legalidade à Base Nacional Comum Curricular do Ensino Médio (BRASIL, 2017), temos a permanência dos princípios tecnicistas como referência basilar que visa organizar o sistema público de ensino.

Como parte do movimento de contra tendência, a defesa do acesso irrestrito à educação pública deve ser acompanhada da defesa de um ensino formador omnilateral que, para além do trabalho, implica o desafio de pensar a escola como espaço cujo acesso ao conhecimento contém potencial civilizatório, o qual deve ser utilizado em oposição às inúmeras formas de manifestação da barbárie social no tempo presente. 


\section{O manifesto dos pioneiros e a expansão do ensino público}

As discussões iniciadas na década de 1930 sobre a importância da educação pública gratuita, bem como a montagem que se seguiu do Sistema Nacional de Ensino, são ações que devem ser apreendidas em seu sentido político, histórico e social, pela inerente necessidade em suplantar os limites de uma economia frágil, baseada na monocultura do café. Tratou-se de processos responsáveis em promover profundas transformações na plataforma econômica do país, de modo a permitir, em fins da década de 1950, uma alteração substancial do parque industrial brasileiro. Para Cury (1978, p. 10), “[...] a conversão da estrutura econômica, social e política e a própria mentalidade de vários setores da população, implicavam [a] reconversão da estrutura educacional, a fim de valorizar as novas aspirações e na medida do possível concretizá-las". De fato, superar a dependência do modelo produtivo pautado em uma economia agrário-exportadora de commodities consistiu no maior desafio.

Conforme destaca Carvalho (2012, p. 63), "[...] no limiar dos anos 30, a economia mundial mergulhou na mais catastrófica depressão da história do capitalismo". O Brasil do café acompanhou essa tendência de crise e expôs sua vulnerabilidade econômica; por essa mesma razão, fazia-se necessário promover a transição. De acordo com Romanelli (1986, p. 48), “[...] do setor tradicional para o moderno, ou seja, da área agrícola para a industrial". Assim, as medidas tomadas por Vargas, ao mesmo tempo que serviram para o enfrentamento da crise, objetivaram a sustentação da atividade econômica, o que contribuiu para a criação de condições mais favoráveis ao desenvolvimento industrial.

Em condições análogas ao processo mais geral que acompanhou as transformações dos modos de produção capitalista, em uma perspectiva histórica, tivemos que a manufatura criou as condições para a superação da economia predominantemente agrícola, estabelecendo as bases para o surgimento da grande indústria, da nova economia capitalista industrial propriamente dita. Marx (2008, p. 415), ao analisar esse processo social, indicou que esta revoluciona inteiramente o trabalhador e "[...] se apodera da força individual de trabalho em suas raízes. Deforma o trabalhador monstruosamente, levando-o, artificialmente, a desenvolver uma habilidade parcial, à custa da repressão de um mundo de instintos e capacidades produtivas" (MARX, 2008, p. 415).

A partir da análise de Marx, temos que as relações de trabalho na modernidade se metamorfosearam de modo a atender às necessidades do capital, "[...] no sistema capitalista, a classe dominante objetiva a manutenção do sistema de propriedade privada, a divisão entre capital e trabalho e as relações sociais estabelecidas em termos de mercadoria" (CURY, 1978, p. 5). Nesse caso, a divisão do trabalho incide sobre a atividade laboral, pois cria um rol de novas profissões que decorrem justamente do trabalho parcial, fato este que expropria do trabalhador seu "tempo livre", pois, ao criar novas profissões, o próprio conteúdo da fábrica estende-se às demais instâncias do convívio social. "[...] não dispondo de tempo livre, os trabalhadores acabam não realizando experiências formativas, nem no trabalho nem fora dele" (GALUCH; PALANGANA, 2008, p. 71). Esse emergente modo de produção, como apresentado por Marx (2008), também produziu uma nova economia, uma nova política e uma nova sociedade que exigiu uma força de trabalho capaz de ajustar-se aos novos métodos de trabalho.

No âmbito da escolarização pública, sintonizada às necessidades do capitalismo, a compreensão dos conteúdos a serem ensinados tende a restringir-se ao saber útil correlato às profissões que resultam da atividade laboral parcial. Cury $(1978$, p. 18) destaca que "[...] até 1930 as necessidades do país ainda comportavam, com a oligarquia no poder, um tipo de educação voltada para a satisfação de interesses oligárquicos [...]”; desse modo, as "[...] amplas camadas da população eram marginalizadas do processo educativo escolar. A educação atende exclusivamente as elites”. Contudo, o Brasil do período varguista vivia 
justamente o desafio de desenvolver a indústria e criar uma nova força de trabalho alfabetizada e condizente com a nova plataforma produtiva.

Ao analisarmos o Manifesto dos Pioneiros, verificamos que suas teses relativas à formação da nação contribuíram para o processo de ampliação do sistema de ensino público. Para Vidal (2013, p. 585), “[...] não deixa de ser elucidativo perceber o Manifesto como parte do jogo político pela disputa do controle do Estado [...]. O documento também foi representante de um grupo de intelectuais que abraçava um mesmo projeto de nação [...]". A ampliação da escola pública ficou implícita na análise realizada por Vidal (2013), em seu artigo 80 anos do Manifesto dos Pioneiros da Educação Nova: questões para debate, em que a autora afirma que "[...] o Manifesto sobreviveu como uma carta de princípios pedagógicos, como um marco em prol de uma escola renovada, mas principalmente em defesa da responsabilidade do Estado pela difusão da educação pública no país" (VIDAL, 2013, p. 586). Nas palavras de Vidal (2013, p. 584), o Manifesto "[...] não se situava no estrito âmbito da disputa no campo educacional, representando também uma pregação de natureza macro política". A importância do documento pode ser dimensionada pela relevância de seus signatários. ${ }^{1}$

O Manifesto dos Pioneiros propunha que a educação, como responsabilidade do Estado, deveria incorporar o maior número possível de cidadãos em quaisquer de seus graus, acessível não a uma minoria, por um privilégio econômico, mas a todos os cidadãos que tivessem vontade e estivessem em condições de recebê-la. Aliás, o Estado não poderia tornar o ensino obrigatório, sem torná-lo gratuito (MANIFESTO DOS PIONEIROS, 2006, p. 193). É nesse mesmo sentido que Cury (1978) afirma que "[...] a difusão da escola provocaria as mudanças sociais, acomodando as diferentes classes sociais pela própria ascensão que a mesma geraria" (CURY, 1978, p. 18-19). Nessa perspectiva, acrescenta-se a emblemática passagem contida no Manifesto dos Pioneiros (2006) informando que era preciso "[...] pôr em via de solução o problema educacional das massas rurais e do elemento trabalhador da cidade e dos centros industriais já pela extensão da escola do trabalho educativo e da escola do trabalho profissional [...]" (MANIFESTO DOS PIONEIROS, 2006, p. 197).

Nesse contexto, a educação foi vista como meio capaz de disseminar modos sociais de caráter civilizatório. Por essa razão, “[...] nas escolas o trabalho aparece como elemento central do progresso material, para a satisfação das necessidades materiais e não como libertador do espírito, aparece ainda como elemento central na produção do novo homem" (ARROYO, 2012, p. 120). A expansão da educação pública, conforme apresentada pelo Manifesto dos Pioneiros, sob um determinado ângulo de análise, pode ser concebida como um movimento educacional/civilizatório em que se reivindicou '[...] para a educação a função de 'criar' cidadãos e de reproduzir/modernizar as 'elites', simultaneamente à de contribuir para o trato da questão social” (SHIROMA; MORAES; EVANGELISTA, 2011, p. 12-13).

Como parte do novo direcionamento dado à escola pública, observamos a tentativa de elaboração de um planejamento educacional/profissional de elevação da escola à categoria de instituição capaz de redimir-nos das mazelas sociais por meio da disseminação da cultura e da aprendizagem de ofícios. Portanto, se, por um longo período da história brasileira, a educação pública foi majoritariamente destinada à formação da elite, a década de 1930 foi marcada pela discussão de um novo formato de educação, pois, dentro das necessidades emergentes, o analfabeto precisava ser educado, alfabetizado e instrumentalizado. Nesse sentido, Xavier (2002, p. 15) conclui que, “[...] de acordo com o Manifesto, era necessário que esse homem

\footnotetext{
${ }^{1}$ Assinaram o Manifesto: Fernando de Azevedo; Afranio Peixoto A. de Sampaio Doria; Anisio Spinola Teixeira; M. Bergstrom Lourenço Filho; Roquette Pinto; J. G. Frota Pessôa; Julio de Mesquita Filho; Raul Briquet Mario Casassanta; C. Delgado de Carvalho; A. Ferreira de Almeida Jr.; J. P. Fontenelle; Roldão Lopes de Barros; Noemy M. da Silveira; Hermes Lima; Attilio Vivacqua; Francisco Venancio Filho; Paulo Maranhão, Cecilia Meirelles; Edgar Sussekind de Mendonça; Armanda Alvaro Alberto; Garcia de Rezende; Nobrega da Cunha; Paschoal Lemme e Raul Gomes (Revista HISTEDBR On-line, Campinas, n. especial, p.188-204, ago. 2006).
} 
adquirisse um novo parâmetro de interpretação da realidade, ou seja, um parâmetro racional de compreensão de sua vida individual e da sociedade como um todo".

Por tratar-se de um processo imerso em contradições, Arroyo (2012) salienta que a classe burguesa nada tem a ganhar com o tradicionalismo e a ignorância do povo. Para o autor, um mínimo de modernidade será condição para sobrevivência. Assim, ele compara a inserção na escola como pegar um ônibus, sendo este um meio necessário para chegar ao trabalho, garantir o emprego e sobreviver. A escolarização da classe trabalhadora passou a ser condição mínima para atender à lógica da sociedade capitalista. "O povo é obrigado a trabalhar para sobreviver e tem que lutar pelos instrumentos que o levem e conduzam até o trabalho" (ARROYO, 2012, p. 122-123). Assim, no contexto histórico da década de 1930, houve a nítida relação entre a busca pela ampliação do acesso à educação pública e o movimento que associa ensino e trabalho, a relação intrínseca entre educação e processo industrial, pois é "[...] pelo trabalho que a sociedade se entrega para educar os seus filhos" (MANIFESTO DOS PIONEIROS, 2006, p. 191).

Paralelamente às medidas do Estado no sentido de promover a industrialização, havia a necessidade de promover a expansão da educação pública associando a aprendizagem à aquisição de um ofício/profissão. O Manifesto dos Pioneiros apresentou não apenas a reforma no formato administrativo e sistêmico da educação, ele propunha uma orientação em relação à estrutura do ensino público e dos conhecimentos transmitidos, como das metodologias a serem adotadas. O Manifesto anunciou o novo pragmatismo na educação, um ensino totalmente laico, uma educação pública, obrigatória e gratuita. Para isso, recorreu ao modelo pedagógico da educação nova ou escola nova que "[...] se propõe ao fim de servir não aos interesses de classes, mas aos interesses do indivíduo, e que se funda sobre o princípio da vinculação da escola com o meio social, tem o seu ideal condicionado pela vida social atual, mas profundamente humano, de solidariedade, de serviço social e cooperação [...]" (MANIFESTO DOS PIONEIROS, 2006, p. 191-192).

Ao pragmatismo do Manifesto, devemos acrescentar o equívoco analítico ao sugerir que o processo educação/ensino situa-se acima das classes antagônicas em favor do indivíduo. No sistema capitalista, os indivíduos invariavelmente pertencem a uma das classes, de forma alguma o indivíduo se sobrepõe ou situa-se fora delas. Ao negar a relação entre educação e classes sociais, contraditoriamente, elabora-se uma tese confusa na qual a escola se funda, se alicerça nos princípios de solidariedade e na cooperação. Os interesses das classes diluem-se em uma interpretação social ambígua que objetiva reestabelecer o espírito de disciplina, solidariedade e cooperação entre os homens. "[...] o postulado fundamental da nova teoria educacional é que a natureza humana tende a realizar-se a si mesma, desde que haja controle de si e do meio, exigindo do próprio educando virtudes como esforço, paciência e coragem" (CURY, 1978, p. 85).

Desse modo, a expansão do ensino público representava a consolidação do novo projeto da classe hegemônica, processo atestado pelo dualismo educacional entre a escola formatada para o trabalhador e a escola privada direcionada a segmentos da elite, focada no ensino propedêutico que habilitava para o acesso ao Ensino Superior. Era, assim, excludente para os segmentos que compunham o novo proletariado. Para o trabalhador, a expansão da educação implicava uma mescla entre os investimentos realizados em escolas do ensino regular e escolas técnicas, pois "[...] educar para o trabalho, deste modo, passa a ser uma política educacional de destaque" (DOMINSCHECK, 2015, p. 205).

Essas novas proposições no campo da educação e do ensino vieram acompanhadas de outras ações como a criação do Ministério da Educação e Saúde; o estabelecimento do ensino público primário obrigatório em 1934; a implantação do Plano Geral Nacional de Viação (PGNV) de 1934, que, além da ampliação das linhas férreas, contemplou a construção da malha rodoviária, resultando na criação do Departamento Nacional de Estradas de Rodagens (DNER) 
em 1937. Dessa maneira, um conjunto de ações estatais, articuladas às ocorridas na década de 1940, sedimentou as condições para as transformações econômicas ocorridas nas décadas seguintes, particularmente o processo de industrialização iniciado em 1955.

\section{O Estado Novo e o pragmatismo tecnicista da Reforma Capanema}

No ano de 1937, com a implantação do Estado Novo, “[...] a nova Constituição dedicou bem menos espaço à educação do que a anterior, mas o suficiente para incluí-la num quadro estratégico com vistas a equacionar a 'questão social' e combater a subversão ideológica" (SHIROMA; MORAES; EVANGELISTA, 2011, p. 22). Aprofundaram-se as relações entre o sistema educacional e o sistema econômico. Do ponto de vista do movimento renovador, a ideia do plano educacional permaneceu; no entanto, o conteúdo que a princípio era entendido como instrumento de introdução da racionalidade científica na política educacional reverteu-se de racionalidade de controle político-ideológico, transformando-se em um roteiro seguido pelo governo de Getúlio Vargas em relação às providências tomadas no âmbito educacional. Marcon (2017) indica ter ocorrido uma atuação conjunta entre o Estado e os empresários da indústria, do comércio e da agricultura, pois ambos os segmentos objetivavam a formação de uma classe operária de novo perfil. Segundo Marcon (2017, p. 26), "[...] uma força de trabalho mais colaborativa, capaz de impulsionar o projeto de desenvolvimento econômico e da indústria nacional".

Para Batista (2015), a defesa do ensino racional deu-se de forma mais efetiva nesse período. Para o autor, a considerar a emergência do taylorismo/fordismo na produção, a racionalização do trabalho buscava a preparação de jovens para as empresas. No campo educacional, os cursos adotaram a mesma premissa da racionalização e ensinaram, a partir da lógica desse modelo produtivo, preocupando-se com a eficiência no trabalho, a melhoria da qualidade e o aumento da produção, e a força de trabalho deveria adequar-se "[...] à sua função social produtiva, o que significava um comportamento mais adequado à disciplina exigida pela nova racionalização do trabalho no interior das fábricas", pois, dessa maneira, “[...] o operário seria um trabalhador honrado que contribuiria para a ordem do país, evitando prejuízos ao progresso econômico, projetado pelo Estado e capital" (MARCON, 2017, p. 27). Dessa forma, o capital procurou manter sua hegemonia com base no controle ideológico do trabalhador e "[...] divulgava suas teses via revista IDORT, fazendo discurso para o operariado de conciliação de classe, colaboração, disciplina, todos unidos em prol do progresso do país" (BATISTA, 2010, p. 287).

O progresso econômico apoiava-se nas políticas do Nacional Desenvolvimentismo. Nesse caso, o Estado atuava como planejador, financiador, interventor, administrador e proprietário de empresas estatais. As iniciativas do nacional-desenvolvimentismo podem ser constatadas nos empreendimentos efetivados no período de 1934 a 1953, com destaque para a criação da Justiça do Trabalho (1939) e a Consolidação das Leis do Trabalho (1943). Dentre os empreendimentos realizados, destacam-se as empresas estatais como Instituto Brasileiro de Geografia e Estatísticas (1934); Companhia Siderúrgica Nacional (1941); Companhia Vale do Rio Doce (1942); Fábrica Nacional de Motores (1942); Hidrelétrica do Vale do São Francisco (1945); Banco Nacional de Desenvolvimento Econômico e Social (1952); e Petrobrás S/A (1953). A ideologia do desenvolvimentismo apoiava-se na tese de superação do subdesenvolvimento identificado na ausência de indústrias estatais e privadas competitivas, Estado não atuante, pobreza da população e analfabetismo sistêmico. Nesse cenário, “[...] a educação é compreendida como um instrumento para promover o crescimento e reduzir a pobreza" (OLIVEIRA, 2010, p. 219).

Os novos métodos aplicados para o controle do trabalho nas empresas contribuíram para o aumento da produção. Caracterizaram-se pela rigidez, pela dissociação entre o trabalho intelectual e manual, pela obediência, pelas tarefas com movimentos repetitivos, pela alienação do trabalhador e pelo controle da sua vida fabril e privada, pelo controle cronometrado do tempo 
de fabricação. Conforme asseverou Marcon (2017, p. 28), “[...] a racionalização do trabalho, a qual deveria refletir sobre as condutas cotidianas dos trabalhadores, tem base em pressupostos da organização científica do trabalho, coadunados ao modelo de gestão fordista/taylorista".

Os métodos de racionalização da produção passaram a fazer parte da vida do trabalhador dentro e fora da fábrica. "[...] os novos métodos de trabalho estão indissoluvelmente ligados a um determinado modo de viver, de pensar e de sentir a vida: não é possível obter êxito num campo sem obter resultados tangíveis no outro" (GRAMSCI, 1980, p. 393 apud GALUCH; PALANGANA, 2008, p. 78-79). Na educação, essa racionalidade foi incorporada pela Reforma de Gustavo Capanema que, por meio de decretos, redefiniu a incipiente educação pública brasileira. A educação articulada à necessidade socialmente imposta pelos meios de produção tornou-se, porém, racional e pragmática tal qual o trabalho na fábrica, aprofundando o dualismo entre a escola para as elites e a escola para as classes subalternas. De acordo com Carvalho (2012, p. 147), “[...] o contraste entre a educação popular e a educação destinada às elites condutoras pode ser observado claramente nas reformas do ensino empreendidas a partir de 1942".

Os Decretos-leis ou Leis Orgânicas do Ensino implantadas, conhecidas como Reformas de Capanema, totalizaram oito reformas, quatro delas implantadas por Gustavo Capanema e outras quatro pelo seu sucessor no Ministério da Educação, Raul Leitão da Cunha. Os Decretosleis criaram instituições que tinham por objetivo formar mão de obra qualificada - formação técnica profissional - visando atender às necessidades das indústrias. Nesse sentido, foram ofertadas duas formações distintas, uma pautada no ensinamento rápido e outra de aprendizagem, destinadas à qualificação de aprendizes industriais (ROMANELLI, 1986).

A primeira era correspondente ao Decreto-lei No 4.073, de 30 de janeiro de 1942 - Lei Orgânica do Ensino Industrial, com um ensino direcionado prioritariamente à indústria em expansão no dado momento histórico (BRASIL, 1942b). O desdobramento desse Decreto-lei objetivou, segundo Romanelli (1986, p. 166), “[...] a preparação dos aprendizes menores dos estabelecimentos industriais, cursos de formação e continuação para os trabalhadores não sujeitos à aprendizagem". O que diferenciava os dois Decretos-leis, portanto, era que o primeiro foi mantido pelo Estado, enquanto o Decreto-lei $\mathrm{N}^{\circ} 4.048$, de 22 janeiro de 1942, que criou o Senai, teve como mantenedora a iniciativa privada, representada pelos industriais que selecionavam os melhores alunos (BRASIL, 1942a).

O Decreto-lei No 4.244, de 9 de abril de 1942 - Lei Orgânica do Ensino Secundário, era voltado à formação das "elites condutoras" (BRASIL, 1942c), dado o fato de que a formação era destinada àqueles que optavam por prosseguir para um nível mais elevado de ensino. Assim, como foi criado o Decreto-lei para o ensino industrial, também foi criado o Decreto-lei para o Ensino Comercial, conhecido por Lei Orgânica do Ensino Comercial (Decreto-lei $\mathrm{N}^{\circ}$ 6.141, de 28 de dezembro de 1943), com a finalidade de ofertar cursos direcionados aos empregados do comércio (BRASIL, 1943).

Outros decretos-leis foram criados após 1945, durante o Governo Provisório de José Linhares. Dentre os decretos aprovados no governo provisório, tivemos a Lei Orgânica do Ensino Primário; Ensino Normal; Senac e Ensino Agrícola. Com o Decreto-lei No 8.529, de 2 de janeiro de 1946, o ensino primário foi dividido em duas etapas - categorias diferentes - a primeira, ensino primário fundamental, com duração de cinco anos (quatro anos para o primário elementar e um ano para o primário complementar), direcionado ao atendimento de crianças entre 7-12 anos; a segunda categoria foi o ensino primário supletivo, com duração de dois anos, direcionado ao público adolescente e adulto que não concluiu em idade própria o ensino primário (BRASIL, 1946a).

A Lei Orgânica Ensino Normal (Decreto-lei No 8.530, de 2 de janeiro de 1946) (BRASIL, 1946b) destinou-se à formação do pessoal docente, à habilitação de administradores escolares e a desenvolver e propagar os conhecimentos e as técnicas para formação dentro da seguinte estrutura: o primeiro nível ou ciclo foi atendido nas escolas normais regionais, com 
duração de quatro anos, direcionado à formação de regentes de ensino primário; o segundo nível ou ciclo foi atendido nas escolas normais, com duração de três anos, direcionado à formação de professores primários.

O Serviço Nacional de Aprendizagem Comercial (SENAC) foi criado por meio dos Decretos-leis No 8.621, de 10 de janeiro de 1946 (BRASIL, 1946c) e No $^{o} .622$, de 10 de janeiro de 1946 (BRASIL, 1946d), com o objetivo principal de formar profissionais aptos ao exercício das atividades comerciais, tal qual ocorreu com o Senai. Por fim, a Lei Orgânica Ensino Agrícola, embora seu direcionamento não fosse diferente dos demais documentos, com a estrutura pautada para a formação técnica/profissional do ensino agrícola. Segundo Romanelli (1986, p. 156), “[...] sua organização baseada em dois ciclos: o básico agrícola de quatro anos e o de mestria, de dois anos, no primeiro ciclo, e vários cursos técnicos de três anos, no segundo ciclo [...]".

Diante do exposto, elucida-se que tais Decretos-leis tinham por objetivo a manutenção do dualismo educacional: por um lado, os ensinos secundário e superior continuaram destinando-se às elites; por outro lado, o ensino profissional e as escolas primárias do sistema educacional foram direcionados às camadas populares, em outras palavras, à formação de estoque de força de trabalho por meio da expansão da educação pública. Sobre a temática, Marcon (2017, p. 42) afirma que "[...] o modo de produção capitalista faz da escola mais um espaço contributivo de reprodução social em concordância com a lógica do capital que, contraditoriamente, incorpora as possibilidades e potencialidades humanas".

Nesse processo de ampliação da indústria brasileira e dualização da educação, valorizou-se o conhecimento instrumental, ou seja, as competências instrumentais básicas para atender às necessidades do processo produtivo. Assim, os Decretos-leis deram origem ao que atualmente conhecemos como sendo o Sistema S, com destaque para os atuais Serviço Social do Comércio (Sesc), Serviço Nacional de Aprendizagem Comercial (Senac), Serviço Social da Indústria (Sesi), Serviço Nacional de Aprendizagem Industrial (Senai).

As transformações produzidas nas relações de produção e, sobretudo, o aumento populacional nos centros urbanos, incidiu na necessidade de eliminar o analfabetismo ao passo que exigiu a qualificação para o trabalho; desse modo, têm-se que "[...] o capitalismo, notadamente o capitalismo industrial, engendra a necessidade de fornecer conhecimentos a camadas cada vez mais numerosas, seja pelas exigências da própria produção, seja pelas necessidades do consumo que essa produção acarreta" (ROMANELLI, 1986, p. 59). Não obstante, a necessidade de força de trabalho qualificada para as empresas tornou os cursos técnicos profissionalizantes uma resposta rápida à demanda do mercado. Por outro lado, os trabalhadores incorporaram a ideia de que o ensino se reduz aos parcos conhecimentos necessários para a realização do trabalho, um conhecimento adequado à elevação dos índices de produtividade. Inicialmente trata-se de uma fala direcionada aos amplos segmentos do proletariado, mas que, posteriormente, foi difundido por meio da "sofisticada" teoria do capital humano, mais especificamente nas décadas de 1960 e 1970.

\section{O Nacional Desenvolvimentismo de JK e o neopragmatismo tecnicista}

Até aqui, demonstramos que a expansão da educação pública e profissional no país no decorrer da década de 1940 foi resultado das pressões provocadas pelas demandas sociais emanadas da implantação do "novo" capitalismo brasileiro. Na década seguinte, o rumo do desenvolvimento econômico ganhou um novo fôlego com a abertura do mercado interno ao capital internacional a partir do governo Juscelino Kubitschek (1956-1961). O novo padrão desenvolvimentista apoiou-se na tese da ampliação da economia, em um novo impulso ancorado em uma produção nacional mais desnacionalizada, abrindo possibilidades para a entrada de um volume considerável de capitais oriundos dos EUA e da Europa. Sobre esse contexto, Romanelli (1986, p. 53) afirma que "[...] com Juscelino, acentua-se a implantação da 
indústria pesada no Brasil, mas ganha também novas formas a entrada de capital internacional, através da implantação de filiais das multinacionais". A autora destaca ainda que "[...] no setor político, se dá continuidade ao modelo getulista, no setor econômico abrem-se amplamente as portas da economia nacional ao capital internacional".

A implantação da indústria pesada no país foi uma das ações realizadas por Juscelino Kubitschek (JK), por meio de seu programa Plano de Metas: 50 anos em cinco. O presidente, em seus discursos, afirmava que o objetivo era proporcionar ao país 50 anos de progresso em cinco anos de realizações. O plano foi composto por 30 metas, distribuídas em cinco eixos. $\mathrm{O}$ Estado realizou investimentos nos setores de energia, de transportes, de alimentação, de indústria e de educação (BRASIL, 1958).

A política de desenvolvimento econômico do Presidente Juscelino Kubitschek consubstancia-se em seu programa de metas, que abrange projetos a serem executados com recursos públicos e privados. $\mathrm{O}$ programa traduz um conjunto dinâmico e progressivo de obras e empreendimentos realizáveis em diversas etapas, algumas das quais deverão ser ultimadas até o fim do atual quinquênio de Governo (1961) e outras de conclusão prevista de 5 a 10 anos, como é o caso da meta de energia elétrica, na qual cêrca e $40 \%$ dos investimentos em curso só serão consumados entre 1961 e 1965 (BRASIL, 1958, p. 9).

Ao considerar a importância estratégica do setor de energia, um volume expressivo de investimentos foi direcionado para a instalação, a produção e a distribuição de energia elétrica, evidentemente sem desconsiderar um volume menor de investimentos realizados nas áreas da energia nuclear, carvão mineral e petróleo. No setor de transportes, priorizou-se o transporte rodoviário, complementados pelos meios de transporte ferroviário, aéreo e naval. No setor de alimentação, foi realizado menor investimento, seguido do setor educacional focado na intensificação da formação do pessoal técnico, com vistas a atender a demanda empresarial pressionada pelos investimentos realizados no setor industrial, em especial nos setores de bens de consumo duráveis e bens de capital. Conforme se constata no documento Programa de Metas do Presidente Juscelino Kubitschek: "O plano de metas visa dotar o país de uma infra e superestrutura industrial e modificar sua conjuntura econômica; se não ocorrer interligação desse Plano com os demais fenômenos econômicos, sociais e políticos, o plano tornar-se-á falho" (BRASIL, 1958, p. 95).

Ficou explícito que, no Programa de Metas, as prioridades se concentraram no setor de transporte, de energia e, por extensão, na educação, expresso até mesmo na ordem de elaboração do documento, visto que a educação se apresenta como último tema. Tratava-se de investimentos imprescindíveis para o desenvolvimento industrial em atendimento ao novo padrão da acumulação capitalista no Brasil. Nesse sentido, o Plano de Metas contribuiu para o impulso da urbanização em regiões como o ABC Paulista e a Grande São Paulo. Conforme afirma Araújo (2012, p. 36), “[...] decorrente deste modelo de desenvolvimento se ergueu uma determinada forma de ocupação espacial urbana que, centrada nas necessidades da indústria monopolista, converteu a região no locus, no espaço privilegiado de reprodução da vida social".

A política nacional desenvolvimentista "desnacionalizada" ancorava-se em políticas de apoio do Estado brasileiro, isenções fiscais, infraestrutura, proteção de mercado, sendo um atrativo para as multinacionais se instalarem no Brasil. Dentre as que compuseram as indústrias de produção de bens de consumo duráveis, tivemos: "Scania Vabis, Mercedes Bens, Chrysler, Volkswagen, Toyota, Sinca, Willys e Vemag" (ARAÚJO, 2012, p. 95). Consequentemente, em torno das indústrias multinacionais, criaram-se cadeias produtivas abrindo espaço para a participação de empresas nacionais, geralmente nos segmentos que exigiam um aporte menor 
de capital. Assim, o Nacional Desenvolvimentismo de JK propôs uma política econômica que buscou um novo formato na produção, permitindo a afirmação definitiva do taylorista/fordista como sendo a forma predominante de gestão e organização do Brasil. A organização e a gestão da produção taylorista/fordista disseminaram novos padrões sociais, resultando na disciplinarização em massa. Essas características foram assim definidas por Pinto (2007, p. 32), no sentido de que "[...] distribuíssem os trabalhadores e suas ferramentas efetivamente ao longo de uma linha, ao padronizar o trabalho em atividades cujas operações eram uniformizadas".

A consolidação desses modelos produtivos implicou a necessidade de uma educação com direcionamentos na profissionalização, pautadas nas formas de organização racionalizada do trabalho. A educação ancorada no taylorismo/fordismo, por finalidade, visava uma formação para atender à demanda de trabalhadores e staff da produção, uma vez que a separação entre concepção e execução exigia tarefas relacionadas às ações intelectuais e instrumentais, cuja formação estava bem definida em função das relações de classes (KUENZER, 1999). Destacamos que a educação nessa nova fase da expansão industrial brasileira incorporou uma espécie de neopragmatismo. Nesse caso, a reafirmação da necessidade de expansão da educação pública não só mantinha o pragmatismo das reformas de Gustavo Capanema, mas buscava ampliar o contingente da força de trabalho disponível, necessidade indelével a considerar a implantação das indústrias monopolistas, da nova inserção da economia brasileira na divisão internacional do trabalho.

São reveladores desse processo os dados apresentados pelo Instituto Brasileiro de Geografia e Estatísticas (IBGE), demonstrando como a educação pública e a educação para a profissionalização expandiu-se vertiginosamente, as matrículas para a década (1950/1960) apresentaram aumento em relação aos períodos anteriores, atingindo os dois níveis de ensino primário e secundário. De acordo com os dados apresentados pelo IBGE, tivemos que, na década de 1950, o ensino profissional público atingiu 273.391 matrículas e 309.249 para a década de 1960, com destaque para o ensino industrial na medida em que o ensino privado do Senai se expandia por quase todo o país. Vale destacarmos que este havia recebido apoio assegurado na Constituição:

A Constituição de 1946 trazia um dispositivo que assegurava a isenção tributária para as instituições de educação, vedando à União, aos Estados e aos Municípios o lançamento de impostos sobre seus bens e serviços, desde que suas rendas fossem integralmente aplicadas no país e para os fins educacionais. Na reforma constitucional de 1965, os privilégios fiscais dessas instituições foram ampliados, estendendo-se a isenção de impostos para suas rendas. A Constituição de 1967 e a Emenda de 1969 mantiveram esse dispositivo. Assim, as escolas privadas passaram a gozar de uma verdadeira imunidade fiscal, o que ampliou suas possibilidades de acumulação de capital. (CUNHA, 2007, p. 812).

Na década de 1960, o crescimento da rede pública e privada de educação do ensino profissional manteve seu ritmo de expansão. O "[...] Senai investiu em cursos sistemáticos de formação, intensificou o treinamento dentro das empresas e buscou parcerias com os Ministérios da Educação e do Trabalho e com o Banco Nacional da Habitação" (SENAI/PR, 2015, p. 3). Assim, nesse período, com a articulação do ensino público com as escolas do Sistema S, ambas as instituições funcionaram como verdadeiras promotoras de uma educação/formação direcionada fundamentalmente para a indústria, comércio e setor de serviços. Conforme aponta Marcon (2017, p. 40), “[...] a criação dos sistemas empresariais de educação profissional social - tal qual o Sesi - teve a responsabilidade/missão de formar, de maneira aligeirada, uma gama maior de pessoas disponíveis para atender à demanda dos setores de produção envolvidos no projeto de desenvolvimento econômico nacional”. 
A formação concebida de forma subordinada à produção contribuiu para o desenvolvimento do ensino técnico. Kuenzer (2011) analisa o desenvolvimento do processo das relações de trabalho voltadas à educação do trabalhador, indicando alguns dos elementos que compõem uma pedagogia instrumentalista que educa para a fábrica. Como afirma a autora, "[...] daí os níveis de instrução serem definidos pelos comportamentos esperados e não por graus de ensino, ao mesmo tempo que se toma a experiência como substituto da escolaridade" (KUENZER, 2011, p. 114), situação comum no modelo educacional tecnicista. A experiência aqui empreendida teve por finalidade substituir o conhecimento escolar pelo conhecimento prático e habitual "saber fazer" com ênfase em uma educação escolar voltada à reprodução do cotidiano.

Ao refletir sobre as dimensões da cotidianidade, Heller (2008, p. 31) enfatiza que "[...] a vida cotidiana é a vida de todo homem. Todos a vivem, sem nenhuma exceção, qualquer que seja seu posto na divisão do trabalho intelectual e físico". Ainda de acordo com a autora, a vida cotidiana é caraterizada por dois traços fundamentais, a saber: a espontaneidade e o pragmatismo. Nesse sentido, apreendemos que os conhecimentos pautados no senso comum levam o indivíduo a viver a espontaneidade acrítica típica das formas entranhadas de vida. Segundo Netto e Carvalho (2007, p. 14), por um lado, "[...] a vida cotidiana, esta vida de todos os dias e de todos os homens, é percebida e apresentada diversamente nas suas múltiplas cores e faces". Por outro lado, a luta pela sua reprodução como força de trabalho impõe ao indivíduo um modo de vida pragmático, alheio à sua condição de classe subalterna.

Sobre a temática do cotidiano, Netto e Carvalho (2007, p.15) asseveram que "[...] todos os estudos sobre a vida cotidiana indicam a complexidade, contraditoriedade e ambiguidade de seu conteúdo. E o que é mais importante, a vida de todos os dias não pode ser recusada ou negada como fonte de conhecimento e prática social". No entanto, a espontaneidade e o pragmatismo contribuem para a perpetuação de um modo de vida alienado que, resultante da subalternidade de classe, implica um complexo processo de embrutecimento social dos indivíduos. Além disso, é necessário considerar que "[...] a vida cotidiana é, para o Estado e para as forças capitalistas, fonte de exploração e espaço a ser controlado, organizado e programado" (NETTO; CARVALHO, 2007, p. 20).

No início da década de 1960, foi aprovada a primeira Lei de Diretrizes e Bases da Educação Nacional (LDBEN) e o Plano Nacional de Educação. Vale ressaltarmos que a aprovação dos documentos, a considerar o contexto político do período, recebeu o apoio dos movimentos sociais em luta pela democracia e em defesa das reformas de base propugnada pelo então Presidente João Goulart. De acordo com Shiroma, Moraes e Evangelista (2011, p. 26), “[...] mobilizações populares reivindicavam Reformas de Base - reforma agrária, reforma na estrutura econômica, na educação, reformas, enfim, na estrutura da sociedade brasileira". Essa movimentação repercutiu intensamente no campo da cultura e da Educação. De modo a conter as mobilizações populares, controlar as ações do Estado e preservar a hegemonia das classes dominantes, instalou-se, em 1964, o Regime Militar (1964-1985), que adotou mecanismos de repressão para os opositores.

No campo educacional, para Piletti e Piletti (2014, p. 204): “A partir de 1964, a educação brasileira, da mesma forma que os outros setores da vida nacional, passou a ser vítima do autoritarismo que se instalou no país". Contudo, a política autoritária e centralizadora manteve a lógica de apoio ao capital industrial multinacional instalado no país, acarretando maior endividamento do Estado conforme se verificou na eclosão da crise da dívida externa em fins dos anos de 1970 e início da década de 1980 (TAUILE, 2001). Debruçando-se sobre esse período, Carvalho (2012, p. 179) demonstrou os pilares de sustentação do modelo de crescimento econômico adotado pelo governo militar: 
1) entrada maciça de capitais estrangeiros, na forma de investimento e empréstimos; 2) aprofundamento da exploração da classe trabalhadora submetida ao arrocho salarial e à repressão política; 3) garantia, pelo Estado, da expansão capitalista e da consolidação do grande capital nacional e internacional, especialmente por meio de subsídios e correção monetária como mecanismos de controle inflacionário. (CARVALHO, 2012, p. 179).

Com base no exposto, apreendemos que se formou uma aliança entre as empresas, particularmente as multinacionais, e o Estado, com vistas a acelerar o processo de modernização do capitalismo, ensejando o período do "milagre econômico" (1968-1973). Este era resultante da alta percentagem apresentada no crescimento do Produto Interno Bruto (PIB), atingindo uma média de $10 \%$ ao ano. Por outro lado, Ferreira Jr. e Bittar (2008) afirmaram que tais índices só foram possíveis em função da intensificação da exploração dos trabalhadores brasileiros, desencadeando, ao mesmo tempo, um processo de supressão das liberdades democráticas.

Evidentemente que a conjuntura política do período contribuiu para delinear as teses apresentadas quando da elaboração da Lei de Diretrizes e Bases para a Educação Nacional, Lei $\mathrm{N}^{\mathrm{o}}$ 5.692, de 11 de agosto de 1971, fixando as diretrizes e as bases para o ensino de $1^{\circ}$ e $2^{\circ}$ graus, “[...] pretensiosamente denominada Lei de Diretrizes e Bases do Ensino de $1^{\circ}$ e $2^{\circ}$ Graus, essa política consistiu na fusão dos ramos do $2^{\circ}$ ciclo do ensino médio (na nomenclatura então vigente)" (CUNHA, 2014, p. 914), reiterando a permanência da tendência tecnicista, do ensino como sendo parte do processo de preparação do indivíduo para o trabalho.

Saviani (2010, p. 383) assevera que "[...] do ponto de vista pedagógico, conclui-se que, se para a pedagogia tradicional a questão central é aprender, e para a pedagogia nova, aprender a aprender, para a pedagogia tecnicista o que importa é aprender a fazer". Assim, o "aprender a fazer" não só mantinha os aspectos sociais, como reafirmava o neopragmatismo tecnicista após JK. Kuenzer (1999, p. 167) afirma que esse modelo pedagógico "[...] foi dando origem a propostas que ora se centraram nos conteúdos, ora nas atividades, sem nunca contemplar uma relação entre aluno e conhecimento que verdadeiramente integrasse conteúdo e método, de modo a propiciar o domínio intelectual das práticas sociais e produtivas”. Nesse caso, com base nas premissas da educação instrumental, bastava conceder aos assalariados as informações que permitissem desenvolver habilidades e iniciativas para tomadas de decisões, para a garantia do emprego e do salário diferenciado. Ocorre que as alterações econômicas impulsionaram a reestruturação no campo produtivo, social e político, com repercussões na educação ${ }^{2}$.

A crise de 1973 foi marcada por uma intensa recessão mundial. Como afirma Harvey (2008, p. 140), “[...] em consequência, as décadas de 70 e 80 foram um conturbado período de reestruturação econômica e reajustamento social e político". Essa passagem aponta que a crise de valorização do capital implicou um intenso processo de reestruturação da produção e do trabalho, os quais se desenvolveram pautados na tríade racionalidade, eficiência e produtividade. Dessa forma, nos países capitalistas centrais, nos segmentos produtivos mais desenvolvidos, a rigidez do fordismo foi paulatinamente sendo suplantada pelo modelo "flexível" Toyotista. Trata-se de um novo complexo da restruturação produtiva idealizado pelo engenheiro Taiichi Ohno, um modelo

\footnotetext{
${ }^{2}$ No contexto de afirmação do novo padrão industrial brasileiro, nas décadas de 1970 e 1980 , a considerar o processo de reconfiguração política, surgiram novas propostas de mudanças no campo educacional, especialmente nos meios universitários que, de modo geral, criticavam o ensino tecnicista de viés instrumental. Contudo, as novas propostas de viés progressista não tiveram força contra uma agenda mundial de políticas públicas educacionais, orientadas, especialmente, por organismos internacionais como o Banco Mundial, a Organização das Nações Unidas para a Educação, a Ciência e a Cultura (UNESCO) e a Organização para a Cooperação e Desenvolvimento Econômico (OCDE), sobretudo, em países latino-americanos ou nos chamados países periféricos, que, sob a óptica da política neoliberal, pressupunham a racionalização intensa dos gastos públicos, repassados para iniciativa privada, no intento de modernização do Estado, adequando-o aos novos ditames da ordem internacional.
} 
japonês nascido na Toyota e difundido pelo mundo a partir da década de 1970. Antunes (2009) descreve que os principais traços desse modelo produtivo se relacionam à produção vinculada à demanda, ao trabalho em equipe, à flexibilidade produtiva, ao aproveitamento de todo o tempo, à vinculação do salário com a produção, bem como à exigência de profissionais competentes e habilidosos. Galuch e Palangana (2008) apresentam as consequências desse novo modo produtivo, pautado na acumulação flexível:

desemprego estrutural; o aumento da competição; a exigência de novas habilidades, ao mesmo tempo em que outras desaparecem ou ficam obsoletas; a estagnação dos salários; e, no campo político, enorme perda do poder sindical, diante da, também, flexibilidade nos regimes e contratos de trabalhos nos quais o emprego regular, cada vez mais, cede lugar para os contratos temporários, os subcontratos, a terceirização e os trabalhadores autônomos. Essas transformações são traduzidas por uma nova forma de organização industrial, sobretudo pelo surgimento de pequenos negócios, permitindo, inclusive, o reaparecimento de sistemas de trabalho em desuso, tais como: trabalho artesanal e o familiar. Todavia, há que se observar que esses sistemas de trabalho estão agora, submetidos às grandes empresas. (GALUCH; PALANGANA, 2008, p. 72).

A acumulação flexível “[...] envolve rápidas mudanças dos padrões do desenvolvimento desigual" (HARVEY, 2008, p. 140), passando a educação "[...] a constituir-se num dos fatores fundamentais para explicar economicamente as diferenças de capacidade de trabalho e, consequentemente, as diferenças de produtividade de renda" (FRIGOTTO, 2010, p. 51). Podemos perceber que tanto o desenvolvimento desigual de Harvey (2008) quanto as diferenças de capacidade de trabalho e diferenças de produtividade de renda de Frigotto (2010) são processos densamente relacionados aos aspectos sociais que nos remetem à teoria do capital humano.

\section{Da Teoria do Capital Humano à era destrutiva do capital hegemônico financeirizado}

Importa-nos esclarecer que a história da educação no Brasil até aqui caminhou com direta relação à divisão social e à técnica do trabalho, e os encaminhamentos conduziram-se em consonância às forças sociais em disputa. Nesse sentido, o foco na formação para o trabalho, para a prática e para a teoria deu-se nos cursos oferecidos por instituições da iniciativa privada que compuseram o Sistema S (Senai, Senac e Sesi), local onde a formação técnica foi disseminada e objetivava o uso da força de trabalho no espaço fabril. Já, para a formação na escola pública propriamente dita, foram oferecidos os cursos de cunho "[...] profissionalizantes - destinados a formar técnicos e auxiliares técnicos para as mais diversas atividades econômicas" (CUNHA, 2014, p. 915). Esses cursos apoiavam-se nas premissas teóricas da teoria do capital humano. De acordo com essa teoria, o investimento na formação de pessoas qualificação e no aperfeiçoamento - resultaria na elevação da produtividade, consequentemente aumentaria os lucros dos capitalistas, vinculando a educação ao desenvolvimento econômico.

Cunha (2014, p. 920) asseverou que "[...] a concepção de ensino profissionalizante estava baseada na necessidade de organizar o ensino médio de modo que proporcionasse aos concluintes uma habilitação profissional". De acordo com Saviani (2010, p. 344), esse sentido geral voltado à educação profissional "[...] é traduzido pela ênfase nos elementos dispostos pela teoria do capital humano; na educação como formação de recursos humanos para o desenvolvimento econômico dentro dos parâmetros da ordem capitalista; [...]”, 
exigindo, assim, a formação de aptidões e iniciação para o trabalho encontrado principalmente nos cursos profissionalizantes.

Atendendo às necessidades imediatistas do mundo do trabalho, inspiradas “" [...] nos princípios de racionalidade, eficiência e produtividade, a pedagogia tecnicista advoga a reordenação do processo educativo de maneira que o torne objetivo e operacional" (SAVIANI, 2010, p. 381), ou, também, o processo educativo pode ser entendido como pragmático e disciplinador. Araújo e Oliveira (2017) afirmam que, no contexto que envolve a sociedade capitalista, a educação escolar tem o papel de formar trabalhadores ou futuros trabalhadores, resultando na formação e na reprodução social da força de trabalho.

percebemos que na sociedade capitalista a educação escolar situada na dimensão da superestrutura (ideológica e política) tem o papel de formar os trabalhadores ou os futuros trabalhadores e segue, para tanto, as necessidades impostas pela infraestrutura (base produtiva-econômica) o que implica, por sua vez, na existência de professores cuja 'formação' seja condizente para o exercício adequado de determinadas práticas de ensino, considerando os imperativos contemporâneos para a formação e reprodução social da força de trabalho. (ARAÚJO; OLIVEIRA, 2017, p. 90).

Os autores abordam ainda que a "[...] educação permeia um profícuo campo de disputa" (ARAÚJO; OLIVEIRA, 2017, p. 90). Assim, compreende-se que a teoria do capital humano emergiu do desdobramento da teoria econômica marginalizadora inserida na educação. Frigotto (2010) desvela o conceito de capital humano, afirmando que "[...] a partir de uma visão reducionista busca-se erigir-se como um dos elementos explicativos do desenvolvimento e equidade social e como uma teoria de educação, segue, do ponto de vista da investigação, um caminho tortuoso" (FRIGOTTO, 2010, p. 49).

Na prática, a teoria do capital humano "[...] se constitua em um poderoso instrumento de manutenção do senso comum" (FRIGOTTO, 2010, p. 46), firmando a educação como meio de manutenção da ordem capitalista incorporando as relações de dominação e submissão, fatos que não só dificultam "[...] decifrar os dilemas da educação/ensino, mas obstaculizam a atuação dos agentes envolvidos no sentido da melhoria do ensino no Brasil" (ARAÚJO; OLIVEIRA, 2017, p. 91). Assim, verificou-se que a expansão da educação pública e disciplinadora guarda uma íntima relação com a concepção de educação presente na teoria do capital humano, "[...] daí a difusão da necessidade de mudanças comportamentais, das tomadas de iniciativas, do esforço individual, da formação focada na gestão de recursos próprios e empreendedorismo, isto é, competências técnicas e humanas, fundamentais à organização do trabalho após a reestruturação produtiva" (MARCON, 2017, p. 61).

Se até a década de 1980 os delineamentos da educação estiveram centrados em criar, ampliar e adaptar instituições específicas para o sistema escolar, a fim de garantir a sua função produtora e reprodutora de formação de força de trabalho, nas décadas seguintes, as mudanças científicas e técnicas no mundo do trabalho resultaram no aprofundamento das reestruturações do trabalho produtivo e de serviços. Na produção, além da diminuição dos postos de trabalho, difundiu-se a ideia de empreendedorismo, em que cada indivíduo se torna responsável pelo seu sucesso ou fracasso.

No setor educacional, disseminou-se a necessidade de um ensino/profissionalização mais adequado aos parâmetros do trabalho flexível conforme a tese da educação para todos. Neves e Ponko (2008) asseveram que:

Isso implica simultaneamente a ampliação quantitativa dos anos de escolaridade básica e uma organização curricular voltada mais imediatamente para o desenvolvimento de capacidades técnicas e de 
uma nova sociabilidade das massas trabalhadoras que contribuam para a reprodução ampliada do capital e para a obtenção do seu consentimento ativo para as relações de exploração e dominação burguesas na atualidade. (NEVES; PONKO, 2008, p. 25).

Esse projeto de educação e de sociedade, que envolve a formação de força de trabalho e uma educação para a formação do consenso, encontra-se introduzido na atual Reforma do Ensino Médio, dada pela Lei $N^{\circ}$ 13.415/2017 e na Base Nacional Comum Curricular (BNCC) do Ensino Médio. Nesse sentido, a relação que envolve a formação de capital humano e a educação com características assistencialistas têm sintonia com o conteúdo de tais documentos, que também contaram com uma relação de "indicações de ações", pautadas em objetivos, compromissos e requisitos, focados na premissa de "melhorar a qualidade de vida" ou levar o indivíduo a "aprender a aprender".

Desse processo, decorre o fato de que a Lei $\mathrm{N}^{\circ} 13.415 / 2017$ organiza o ensino por itinerários formativos, e a BNCC, por arranjos curriculares, conforme disposto no art. 36

Art. 36. O currículo do ensino médio será composto pela Base Nacional Comum Curricular e por itinerários formativos, que deverão ser organizados por meio da oferta de diferentes arranjos curriculares, conforme a relevância para o contexto local e a possibilidade dos sistemas de ensino, a saber: I - linguagens e suas tecnologias; II matemática e suas tecnologias; III - ciências da natureza e suas tecnologias; IV - ciências humanas e sociais aplicadas; V - formação técnica e profissional. (BRASIL, 2017, p. 1).

A referida lei acrescenta ainda que, "[...] mediante disponibilidade de vagas na rede" (BRASIL, 2017, p. 2), será possibilitado aos alunos que concluíram o Ensino Médio cursar mais um itinerário formativo. Nesse sentido, Schults (2012, p. 29-30) salienta que "[...] o trabalho da educação é então visto como o da construção da capacidade desses indivíduos, preparando-os para serem eternos estudantes, que precisarão ser credenciados para seus papéis em ocupações mutáveis". Parece-nos que a Reforma do Ensino Médio e a BNCC caminham no mesmo sentido. Como agravante, temos que a Lei $\mathrm{N}^{\circ} 13.415 / 2017$, ao tratar da oferta de formação com ênfase técnica e profissional, indica que; "I - a inclusão de vivências práticas de trabalho no setor produtivo ou em ambientes de simulação, estabelecendo parcerias e fazendo uso, quando aplicável, de instrumentos estabelecidos pela legislação sobre aprendizagem profissional" (BRASIL, 2017, p. 2).

Do exposto, dois aspectos merecem atenção: 1) a inclusão de vivências práticas e a formação para o trabalho que esvazia o conhecimento pautado no estudo das Ciências e Humanidades, aprofundando a formação unilateral; 2) o estabelecimento de parcerias, em consonância com as orientações internacionais, a exemplo da Organização das Nações Unidas (ONU), quando dos Objetivos de Desenvolvimento Sustentável "Transformando Nosso Mundo: A Agenda 2030 para o Desenvolvimento Sustentável”, mais especificamente no objetivo 4 - Educação de Qualidade em seu subtópico 4.3 - "Até 2030, assegurar a igualdade de acesso para todos os homens e mulheres à educação técnica, profissional e superior de qualidade, a preços acessíveis, incluindo universidade" (ONU, 2015, n.p.). Temos que as orientações nacionais e internacionais enfatizam a "parceria" público-privada, como se denota no parágrafo $8^{\circ}$, do art. 36, da Lei $\mathrm{N}^{\circ}$ 13.415/2017: “A oferta de formação técnica e profissional a que se refere o inciso $\mathrm{V}$ do caput, realizada na própria instituição ou em parceria com outras instituições [...]" (BRASIL, 2017, p. 2). 
Dessa forma, temos que as reformas educacionais tendem a aprofundar o histórico pragmatismo tecnicista, acentua os traços da permanente subordinação da educação à necessidades de ampliação do capital, corroborando para processos de concentração de renda e da desigualdade social, aspecto correlato ao desenvolvimento capitalista de características caudatárias, processo que se agrava na medida em que "[...] a crise do capitalismo em sua fase atual recrudesce de modo irreparável a barbárie social" (RIBEIRO; ARAÚJO, 2018, p. 4).

\section{Considerações finais}

Vimos que, na década de 1930, o Manifesto dos Pioneiros de 1932 difundia uma proposta educacional correlata a um projeto de desenvolvimento da nação, de superação dos entraves que obstavam a nação no sentido de trilhar por caminhos civilizatórios. Ainda que o Manifesto sugerisse uma educação alinhada à aprendizagem de ofícios, concepção voltada principalmente às camadas socialmente mais vulneráveis da população, a intervenção do Estado nas ações educacionais públicas e a construção do Sistema Nacional de Ensino representou novas possibilidades para segmentos expressivos da população brasileira, até então sem acesso aos meios necessários para a alfabetização ou formas de trabalhos circunscritas ao meio rural.

Por essa razão, o Manifesto dos Pioneiros de 1932 continha espasmos civilizatórios, pois associava as perspectivas de desenvolvimento econômico da nação às melhorias das condições sociais dos brasileiros. Na década seguinte, a partir das reformas Capanema, prevaleceu o pragmatismo educacional que subordinou o ensino ao trabalho. A vinda das multinacionais, no decorrer dos anos de 1950 e 1960, e as novas exigências do mundo produtivo implicaram a afirmação do modelo taylorista/fordista, cuja rígida forma de organização e gestão da força de trabalho exigiu mudanças no sistema de ensino brasileiro, dinâmica também impulsionada pela introdução da teoria do capital humano. Na guisa desse processo, os entraves à expansão do capital fizeram emergir, no período posterior, a gestão e a organização do trabalho flexível predominantemente toytista. No Brasil, esse modelo assumiu feição sistêmica a partir de 1990.

Como parte de uma mesma processualidade histórica, atualmente podemos observar que as novas reformas do ensino público expressam justamente as tendências sob a hegemonia do capital financeiro. Este não só atua para a obtenção da maior parte do orçamento público via pagamento de títulos da dívida pública, mas limita as promessas de qualquer projeto civilizatório, pois, na outra mão, atua pela retirada de garantias e de direitos do trabalho. A educação técnica e profissional, reservada aos amplos segmentos mais pauperizados do proletariado, tende a limitar-se ao ensino de habilidades e de competências para uso em empregos precários e destituídos de direitos, um verdadeiro retrocesso a considerar as perdas de conquistas sociais das últimas décadas, conforme se verifica por meio das recentes reformas da previdência social e trabalhista. $\mathrm{Na}$ atualidade, as instabilidades daqueles que vivem da venda da sua força de trabalho é correlata às transformações ocorridas no mundo do trabalho que faz imperar o emprego intermitente sem garantias ou proteção, da baixa qualificação exigida e disponibilidade de tempo máxima conforme o processo de uberização. Nesse contexto, são exigidos dos assalariados que desenvolvam a capacidade de desenvolver resiliência, mobilização e disposição física/psíquica, processo consonante às novas habilidades e competências preconizadas pela BNCC do Ensino Médio.

\section{Referências}

ANTUNES, Ricardo. Os sentidos do trabalho - ensaio sobre afirmação e a negação do trabalho. 2. ed. São Paulo: Boitempo, 2009. 
ARAÚJO, Renan. Desenvolvimento tardio e a nova degradação do trabalho: os significados sociais da reforma do ensino médio no Brasil. In: ARAÚJO, Renan. (org.). Trabalho e educação: os dilemas do ensino público no Brasil. Curitiba: CRV, 2018. p. 45-60.

ARAÚJO, Renan. O novo perfil metalúrgico do ABC: um estudo sobre o trabalho e o modo de vida "just-in-time" do metalúrgico jovem-adulto flexível (1992-2008). Campo Mourão: Fecilcam, 2012.

ARAÚJO, Renan; OLIVEIRA, Helen Cristina de. Implicações da lógica da teoria do capital humano sobre o trabalho educativo: um olhar histórico. Pedagogia em Foco, Iturama, v. 12, n. 7, p. 88-101, jan./jun. 2017.

ARROYO, Miguel G. O direito do trabalhador à educação. In: GOMEZ, Carlos Minayo et al . (orgs.). Trabalho e conhecimento: dilemas na educação do trabalhador. 6. ed. São Paulo: Cortez, 2012. p. 103-127.

BATISTA, Eraldo Leme. A educação profissional no Brasil: análise sobre o centro ferroviário de ensino e seleção profissional - década de 1930. In: BATISTA, Eraldo Leme; MÜLLER, Meire Terezinha. (Orgs.). Realidades da educação profissional no Brasil. São Paulo: Ícone, 2015. p. 165-178.

BATISTA, Eraldo Leme. Trabalho, ideologia e educação profissional no Brasil: análise da visão industrial nas décadas de 1930 e 1940. In: SOUZA, José dos Santos; ARAÚJO, Renan. (orgs.). Trabalho, educação e sociabilidade. Maringá: Praxis, Massoni, 2010. p. 285-305.

BRASIL. Decreto-lei No 4.048, de 22 de janeiro de 1942. Cria o Serviço Nacional de Aprendizagem dos Industriários (SENAI). Brasília: Presidência da República, Casa Civil, Subchefia para Assuntos Jurídicos, [1942a]. Disponível em: http://www.planalto.gov.br/ccivil 03/Decreto-Lei/19371946/Del4048.htm. Acesso em: 10 set. 2019.

BRASIL. Decreto-lei No 4.073, de 30 de janeiro de 1942. Lei orgânica do ensino industrial. Brasília: Presidência da República, Casa Civil, Subchefia para Assuntos Jurídicos, [1942b]. Disponível em: http://www.planalto.gov.br/ccivil 03/Decreto-Lei/1937-1946/Del4073.htm. Acesso em: 10 set. 2019.

BRASIL. Decreto-lei $N^{\circ}$ 4.244, de 9 de abril de 1942. Lei orgânica do ensino secundário. Brasília: Presidência da República, Casa Civil, Subchefia para Assuntos Jurídicos, [1942c]. Disponível em: http://www.planalto.gov.br/ccivil 03/decreto-lei/1937-1946/Del4244.htm. Acesso em: 10 set. 2019.

BRASIL. Decreto-lei No 6.141, de 28 de dezembro de 1943. Lei Orgânica do Ensino Comercial. Brasília: Presidência da República, Casa Civil, Subchefia para Assuntos Jurídicos, [1943]. Disponível em: http://www.planalto.gov.br/ccivil 03/Decreto-Lei/19371946/Del6141.htm. Acesso em: 10 set. 2019.

BRASIL. Decreto-lei Nº 8.529, de 2 de janeiro de 1946. Lei Orgânica do Ensino Primário. Brasília: Câmara dos Deputados, [1946a]. Disponível em: https://www2.camara.leg.br/legin/fed/declei/1940-1949/decreto-lei-8529-2-janeiro-1946458442-publicacaooriginal-1-pe.html. Acesso em: 10 set. 2019 
BRASIL. Decreto-lei $\mathbf{N}^{\mathbf{0}}$ 8.530, de 2 de janeiro de 1946. Lei Orgânica do Ensino Normal. Brasília: Presidência da República, Casa Civil, Subchefia para Assuntos Jurídicos, [1946b]. Disponível em: http://www.planalto.gov.br/ccivil_03/Decreto-Lei/1937-1946/Del8530.htm. Acesso em: 10 set. 2019.

BRASIL. Decreto-lei $N^{\circ}$ 8.621, de 10 de janeiro de 1946. Dispõe sôbre a criação do Serviço Nacional de Aprendizagem Comercial e dá outras providências. Brasília: Presidência da República, Casa Civil, Subchefia para Assuntos Jurídicos, [1946c]. Disponível em: $\quad$ http://www.planalto.gov.br/ccivil 03/Decreto-Lei/19371946/Del8621.htm. Acesso em: 10 set. 2019.

BRASIL. Decreto-lei $\mathbf{N}^{\mathbf{0}}$ 8.622, de 10 de janeiro de 1946. Dispõe sôbre a aprendizagem dos comerciários, estabelece e deveres dos empregadores e dos trabalhadores menores relativamente a essa aprendizagem e dá outras providências. Brasília: Presidência da República, Casa Civil, Subchefia para Assuntos Jurídicos, [1946d]. Disponível em: http://www.planalto.gov.br/ccivil_03/DecretoLei/1937-1946/Del8622.htm. Acesso em: 10 set. 2019.

BRASIL. Lei N $\mathrm{N}^{\circ}$ 5.692, de 11 de agosto de 1971. Fixa as Diretrizes e Bases da Educação Nacional. Diário Oficial da União: seção 1, Brasília, DF, p. 6377, 12 ago. 1971.

BRASIL. Lei $\mathrm{N}^{\mathrm{o}}$ 13.415, de 16 de fevereiro de 2017. Altera as Leis $\mathrm{N}^{\text {os }} 9.394$, de 20 de dezembro de 1996, que estabelece as diretrizes e bases da educação nacional, e 11.494, de 20 de junho 2007, que regulamenta o Fundo de Manutenção e Desenvolvimento da Educação Básica e de Valorização dos Profissionais da Educação, a Consolidação das Leis do Trabalho CLT, aprovada pelo Decreto-Lei no 5.452, de 1 o de maio de 1943, e o Decreto-Lei no 236, de 28 de fevereiro de 1967; revoga a Lei no 11.161, de 5 de agosto de 2005; e institui a Política de Fomento à Implementação de Escolas de Ensino Médio em Tempo Integral. Diário Oficial da União: seção 1, Brasília, DF, n. 35, p. 1-3, 17 fev. 2017.

BRASIL. Programa de Metas do Presidente Juscelino Kubitschek. Estado do Plano de Desenvolvimento Econômico em 30 de junho de 1958. Rio de Janeiro: Presidência da República, 1958. Disponível em: https://goo.gl/rSJain. Acesso em: 7 fev. 2018.

CARVALHO, Elma Júlia Gonçalves de. Políticas públicas e gestão da Educação no Brasil. Maringá: Eduem, 2012.

CUNHA, Luiz Antônio. Ensino Profissional: o grande fracasso da ditadura. Cadernos de Pesquisa, São Luís, v.44, n.154 p.912-33, out./dez. 2014. https://doi.org/10.1590/198053142913

CUNHA, Luiz Antônio. O desenvolvimento meandroso da educação brasileira entre o Estado e o mercado. Educação \& Sociedade, Campinas, v. 28, n. 100 - Especial, p. 809-829, out. 2007. https://doi.org/10.1590/S0101-73302007000300009

CURY, Carlos Roberto Jamil. Ideologia e educação brasileira. São Paulo: Cortez \& Moraes, 1978.

DOMINSCHEK, Desiré Luciane. Tempos "Modernos" no Brasil? O parque fabril brasileiro e as iniciativas senasianas. In: BATISTA, Eraldo Leme; MÜLLER, Meire Terezinha. (orgs.). Realidades da Educação Profissional no Brasil. São Paulo: Ícone, 2015. p. 201-215. 
FERREIRA JR., Amarilio; BITTAR, Marisa. Educação e ideologia tecnocrática na ditadura militar. Cadernos CEDES, Campinas, v.28, n.76, p.333-55, set./dez. 2008. https://doi.org/10.1590/S0101-32622008000300004

FRIGOTTO, Gaudêncio. A produtividade da escola improdutiva. 9. ed. São Paulo: Cortez, 2010.

GALUCH, Maria Terezinha Bellanda; PALANGANA, Isilda Campaner. Experiência, cultura e formação no contexto das relações de produção capitalistas. InterMeio, Campo Grande, v. 14, n. 28, p. 71-87, jul./dez. 2008.

HARVEY, David. Condição pós-moderna. 17. ed. São Paulo: Loyola, 2008.

HELlER, Agnes. O cotidiano e a história. 8. ed. Tradução Carlos Nelson Coutinho e Leandro Konder. São Paulo: Paz e Terra, 2008.

KUENZER, Acacia Zeneida. As políticas de formação: A constituição da identidade do professor sobrante. Educação \& Sociedade, Campinas, ano XX, n. 68, p. 163-183, dez. 1999.

KUENZER, Acacia Zeneida. Pedagogia da fábrica. 8. ed. São Paulo: Cortez, 2011.

MANIFESTO DOS PIONEIROS. O manifesto dos pioneiros da educação nova (1932): a reconstrução educacional no brasil - ao povo e ao governo. Revista HISTEDBR On-line, Campinas, n. especial, p. 188-204, ago. 2006.

MARCON, Jakeline Placido. Educação e trabalho flexível contemporâneo: o perfil profissional e social do docente do Colégio SESI PR. 2017. 137 f. Dissertação (Mestrado em Ensino: Formação de Docentes Interdisciplinar) - Universidade Estadual do Paraná, Paranavaí, 2017.

MARX, Karl. Contribuição à crítica da economia política. Tradução e introdução Florestan Fernandes. 2. ed. São Paulo: Expressão Popular, 2008.

NETTO, José Paulo; CARVALHO, Maria do Carmo Brant de. Cotidiano: conhecimento e crítica. 7. ed. São Paulo: Cortez, 2007.

NEVES, Lucia M. W.; PRONKO, Marcela A. O mercado do conhecimento e o conhecimento para o mercado. Rio de Janeiro: EPSJV, 2008.

OLIVEIRA, Dalila Andrade. Educação Básica: gestão do trabalho e da pobreza. 2. ed. Petrópolis: Vozes, 2010.

ONU. Organização das Nações Unidas. A Agenda 2030 para o Desenvolvimento Sustentável. Os 17 Objetivos de Desenvolvimento Sustentável: Objetivo 4: educação de Qualidade. Plataforma Agenda 2030, 2015. Disponível em: http://www.agenda2030.org.br/ods/4/. Acesso em: 10 set. 2019.

PILETTI, Claudino; PILETTI, Nelson. História da Educação de Confúcio a Paulo Freire. São Paulo: Contexto, 2014.

PINTO, Geraldo Augusto. A organização do trabalho no século XX: Taylorismo, Fordismo e Toyotismo. São Paulo: Expressão Popular, 2007. 
ROMANELLI, Otaíza de Oliveira. História da educação no Brasil. 8. ed. Petrópolis: Vozes, 1986.

SAVIANI, Dermeval. Escola e democracia. 41. ed. Campinas: Autores Associados, 2009.

SAVIANI, Dermeval. História das ideias pedagógicas no Brasil. 3. ed. rev. Campinas: Autores Associados, 2010.

SCHULTS, Lynette. Governança global, neocolonialismo e respostas democráticas para políticas educacionais. In: GUIMARÃES-IOSIF, Ranilce. (org.). Política e governança educacional: contradições e desafios na promoção da cidadania. Brasília: Liber Livros; Universa, 2012. p. 25-40.

SENAI. Serviço Nacional da Indústria. Manual do Aluno SENAI PR. Edição Revisada e atualizada. 2015. Disponível em: http://www.senaipr.org.br/pronatec/uploadAddress/MANUAL ALUNO senai 2015[65760].pdf. Acesso em: 27 jul. 2017.

SHIROMA, Eneida Oto; MORAES, Maria Célia Marcondes de; EVANGELISTA, Olinda. Política Educacional. 4. ed. Rio de Janeiro: Lamparina, 2011.

TAUILE, José R. Para (re)construir o Brasil contemporâneo: Trabalho, tecnologia e acumulação. Rio de Janeiro: Contraponto, 2001.

VIDAL, Diana Gonçalves. 80 anos do Manifesto dos Pioneiros da Educação Nova: questões para debate. Educação e Pesquisa, São Paulo, v.39, n.3, p.577-88, jul./set. 2013. https://doi.org/10.1590/S1517-97022013005000007 